\title{
Experimental and ab initio Computational Studies on Dimethyl-(4-\{4-\{3- methyl-3-phenyl-cyclobutyl)-thiazol-2-yl]-hydrazonomethyl\}-phenyl)-amine
}

\author{
Çiğdem Yüksektepe, ${ }^{*}$ Hanife Saraçoğlu, ${ }^{\dagger}$ Nezihe Çalışkan, ${ }^{\dagger}$ Ibrahim Yilmaz, ${ }^{\S}$ and Alaaddin Cukurovali ${ }^{\#}$ \\ Department of Physics, Faculty of Science, Cankiri Karatekin University, 18100-Ballica, Cankiri, Turkey \\ *E-mail: yuksekc@yahoo.com,yuksektepe.c@karatekin.edu.tr \\ ${ }^{\dagger}$ Department of Physics Education, Faculty of Education, Ondokuz Mayis University, 55139- Kurupelit, Samsun, Turkey \\ ${ }^{\sharp}$ Department of Physics, Faculty of Arts and Sciences, Ondokuz Mayis University, 55139- Kurupelit, Samsun, Turkey \\ ${ }^{\S}$ Department of Chemistry, Faculty of Science, Karamanoglu Mehmetbey University, 70100-Karaman, Turkey \\ ${ }^{\#}$ Department of Chemistry, Faculty of Science, Firat University, 23119-Elazig, Turkey \\ Received June 14, 2010, Accepted September 24, 2010
}

\begin{abstract}
A new hydrazone derivative compound has been synthesized and characterized by IR, ${ }^{1} \mathrm{H}-\mathrm{NMR},{ }^{13} \mathrm{C}-\mathrm{NMR}$ and UV-vis. spectroscopy techniques, elemental analysis and single-crystal X-ray diffraction (XRD). The new compound crystallizes in monoclinic space group $C 2 / c$. In addition to the crystal structure from X-ray experiment, the molecular geometry, vibrational frequencies and frontier molecular orbitals analysis of the title compound in the ground state have been calculated by using the HF/6-31G(d, p), B3LYP/6-311G(d, p) and B3LYP/6-31G(d, p) methods. The computed vibrational frequencies are used to determine the types of molecular motions associated with each of the observed experimental bands. To determine conformational flexibility, molecular energy profile of (1) was obtained by semi-empirical (AM1) calculation with respect to a selected degree of torsional freedom, which was varied from $-180^{\circ}$ to $+180^{\circ}$ in steps of $10^{\circ}$. Molecular electrostatic potential of the compound was also performed by the theoretical method.
\end{abstract}

Key Words: Synthesis, Crystal structure, Vibrational frequency, DFT

\section{Introduction}

Benzothiazolium groups have been used in organic dyes as either electron-withdrawing or electron-donating substituents, depending on whether the $\mathrm{N}$ atom is cationic or not. ${ }^{1}$ Various thiazole derivatives show herbicidal, anti-inflammatory, antimicrobial and antiparasite activity and also liquid crystal properties. ${ }^{2,4}$ The thiazole ring is known to be a part of vitamin B1, cocarboxylase, and the cyclic system of penicillin. ${ }^{5}$ Thiazole itself and its derivatives are of importance in biological systems as anti-inflammatory, analgesic agents and inhibitors on lipoxygenase activities. ${ }^{6,7}$ Schiff bases constitute an interesting class of chelating agents, capable of coordination with one or more metal ions to form mononuclear as well as polynuclear metal complexes. ${ }^{8,9}$ Some of these applications could be found in analytical chemistry and serve as biochemical models. ${ }^{10,11}$ Most Schiff bases have antibacterial, anticancer, anti-inflammatory and antitoxic activities and the sulfur-containing Schiff bases are particularly effective. ${ }^{12}$ Hydrazone derivatives have been synthesized in order to investigate the relationship between structure and biological activity. ${ }^{13-15}$ Hydrazine has been reported to methylate DNA and interfere in the urea cycle, with the result that citrulline levels are raised in the livers of experimental animals. ${ }^{16-18}$ Substituted hydrazines have also found many scientific and commercial applications. ${ }^{19,20}$ Hydrazones have been utilized for the determination of carbonyl compounds. ${ }^{21,22}$ Taking into account the above observations this compound has been synthesized in a similar manner of our ongoing biological active compounds research program. ${ }^{23}$

A number of papers have recently appeared in the literature concerning the calculation of vibrational assignments by quan- tum-chemistry methods. ${ }^{24-28}$ These papers indicate that geometry optimization is a crucial factor in an accurate determination of computed vibrational frequencies. Moreover, it is known that the density functional theory (DFT) adequately takes into account electron correlation contributions, which are especially important in systems containing extensive electron conjugation and/or electron lone pairs. However, considering that as molecular size increases, computing-time also increases. To optimize computing-time the DFT level was used. It was proposed that the single-point calculation of magnetic shielding by DFT methods was combined with a fast and reliable geometry-optimization procedure at the molecular mechanics level. ${ }^{29}$ In most cases, in order to take into account correlation effects, postHartree-Fock calculations of organic molecules have been performed using (i) Møller-Plesset perturbation methods, which are very time consuming and hence applicable only to small molecular systems, and (ii) density functional theory (DFT) methods, which usually provide significant results at a relatively low computational cost. In this regard, DFT methods have been preferred in the study of large organic molecules, metal complexes and organometallic compounds in all those cases in which the electron correlation contributions were not negligible. $^{30-33}$

In this study, we present results of a detailed investigation of the synthesis and structural characterization of dimethyl-(4\{4-\{3-methyl-3-phenyl-cyclobutyl)-thiazol-2-yl]-hydrazonomethyl $\}$-phenyl)-amine by using single crystal X-ray, ${ }^{1} \mathrm{H}-\mathrm{NMR}$, ${ }^{13} \mathrm{C}-\mathrm{NMR}$ and UV-vis. and quantum chemical methods. The vibrational assignments, and frontier molecular orbitals (FMO) analysis of the title compound in the ground state have been calculated by using the Hartree-Fock (HF)/6-31G(d, p) and DFT 

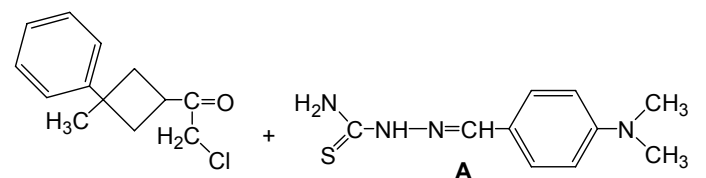

Scheme 1. Synthetic pathway for the synthesis of the target compound

(B3LYP) methods with 6-311G(d, p) and 6-31G(d, p) basis sets. A comparison of the experimental and theoretical spectra can be very useful in making correct assignments and understanding the molecular structure relationship. And so, these calculations are valuable for providing insight into molecular analysis.

\section{Experimental and Theoretical Methods}

General method. IR spectra were recorded on a Mattson 1000 (Unicam Ltd., Cambridge, UK) Fourier transform-infrared (FTIR) Spectrometer using $\mathrm{KBr}$ pellets in the range $4000-400 \mathrm{~cm}^{-1}$. The UV spectra of the compound were performed on a Schimadzu UV-1700 spectrometer in $\mathrm{CHCl}_{3}$ solvent. The ${ }^{1} \mathrm{H}$ and ${ }^{13} \mathrm{C}$-NMR spectra were recorded on a Brucker $400 \mathrm{MHz}$ spectrometer using TMS as internal standard. Microanalyses were performed on a LECO CHNSO-932 auto elemental analysis apparatus. Melting points were determined on a Gallenkamp melting point apparatus and checked by differential scanning calorimeter (DSC) and are uncorrected.

Synthesis. The compound was synthesized as in Scheme 1 by the following procedure. To a solution of hydrazone compound $\mathbf{A}(2.2231 \mathrm{~g}, 10 \mathrm{mmol})$ in $50 \mathrm{~mL}$ of ethanol, a solution of 1-methyl-1-phenyl-3-(2-chloro-1-oxoethyl) cyclobutane $(2.2271 \mathrm{~g}, 10 \mathrm{mmol})$ in $20 \mathrm{~mL}$ of absolute ethanol was added. After the addition of the $\alpha$-haloketone, the temperature was raised to $323-328 \mathrm{~K}$ and kept at this temperature for $2 \mathrm{~h}$. The solution was cooled to room temperature and then made alkaline with an aqueous solution of $\mathrm{NH}_{3}(5 \%)$, and dark brown precipitate separated by suction, washed with aqueous $\mathrm{NH}_{3}$ solution several times and dried in air. Suitable single crystal for crystal structure determination was obtained by slow evaporation of its ethanol solution. Yield: $74 \%$. mp $437 \mathrm{~K}$. IR $\left(\mathrm{KBr}, \mathrm{v} \mathrm{cm}^{-1}\right)$ 3166 (-NH-), 3078 - 3020 (aromatics), 2960 - 2802 (aliphatics), $1606(\mathrm{C}=\mathrm{N}$ azomethine $), 1575(\mathrm{C}=\mathrm{N}$ thiazole $), 703(\mathrm{C}-\mathrm{S}-\mathrm{C}) .{ }^{1} \mathrm{H}-$ NMR $\left(\mathrm{CDCl}_{3}, \mathrm{TMS}, \delta \mathrm{ppm}\right) 1.58\left(\mathrm{~s}, 3 \mathrm{H},-\mathrm{CH}_{3}\right.$, on cyclobutane ring), $2.54\left(\mathrm{~d}, j=8.9 \mathrm{~Hz}, 4 \mathrm{H},-\mathrm{CH}_{2}-\right.$, in cyclobutane ring), 3.03 ( $\mathrm{s}, 6 \mathrm{H},-\mathrm{CH}_{3}$, on aniyine $\mathrm{N}$ ), 3.67 (quint, $j=8.4 \mathrm{~Hz}, 1 \mathrm{H},>\mathrm{CH}-$, in cyclobutane ring), $6.21(\mathrm{~d}, j=0.9 \mathrm{~Hz}, 1 \mathrm{H},=\mathrm{CH}-\mathrm{S}$, in thiazole ring), $6.71(\mathrm{~d}, j=8.95 \mathrm{~Hz}, 2 \mathrm{H}$, on aniline ring), 7.14-7.22 (m, $3 \mathrm{H}$ aromatics), 7.27-7.35 (m, 2H, aromatics), $7.55(\mathrm{~d}, j=8.95 \mathrm{~Hz}$, $2 \mathrm{H}$, on aniline ring), $7.71(\mathrm{~s}, 1 \mathrm{H},-\mathrm{N}=\mathrm{CH}$-, azomethine), $10.56(\mathrm{~s}$, $1 \mathrm{H},-\mathrm{NH}-, \mathrm{D}_{2} \mathrm{O}$ exchangeable). ${ }^{13} \mathrm{C}-\mathrm{NMR}\left(\mathrm{CDCl}_{3}, \mathrm{TMS}, \delta \mathrm{ppm}\right)$ $168.69,155.99,152.35,151.33,142.60,128.20,128.11,125.08$, $124.77,122.01,111.92,101.58,40.26,40.20,38.86,30.84$, 30.14. Anal. calc. for $\mathrm{C}_{23} \mathrm{H}_{26} \mathrm{~N}_{4} \mathrm{~S}(390.54)$; C: 70.73, H: 6.71, N: 14.35, S: 8.21; found; C: 70.57, H: 6.85, N: 13.93, S: 8.34.

Crystal structure determination. The data collection was performed at $293 \mathrm{~K}$ on a Stoe-IPDS-2 diffractometer equipped with a graphite monochromated Mo K $\alpha$ radiation $(\lambda=0.71073$
Table 1. Crystallographic data of (1)

\begin{tabular}{ll}
\hline Empirical Formula & $\mathrm{C}_{23} \mathrm{H}_{26} \mathrm{~N}_{4} \mathrm{~S}$ \\
Molecular Weight & 390.54 \\
Temperature, $\mathrm{T}(\mathrm{K})$ & 296 \\
Wavelength $(\AA)$ & 0.71073 \\
Crystal system & Monoclinic \\
Crystal Size $\left(\mathrm{mm}^{3}\right)$ & $0.540 \times 0.407 \times 0.090$ \\
Space Group & $\mathrm{C} 2 / \mathrm{c}$ \\
$\mathrm{a}(\AA)$ & $23.1133(10)$ \\
$\mathrm{b}(\AA)$ & $6.6096(2)$ \\
$\mathrm{c}(\AA)$ & $31.2925(16)$ \\
$\alpha\left({ }^{\circ}\right)$ & 90 \\
$\beta\left(^{\circ}\right)$ & $115.063(4)$ \\
$\gamma\left({ }^{\circ}\right)$ & 90 \\
Volume, $\mathrm{V}\left(\AA^{3}\right)$ & $4330.4(3)$ \\
$\mathrm{Z}$ & 8 \\
$\mathrm{~T}_{\text {min }}$, $\mathrm{T}_{\text {maks }}$ & $0.9075,0.9689$ \\
Calculated Density $\left(\mathrm{Mg} \mathrm{m}{ }^{-3}\right)$ & 1.198 \\
$\theta$ range $\left({ }^{\circ}\right)$ & $1.44-26.17$ \\
Index Ranges & $\mathrm{h}=-28 \rightarrow 28, \mathrm{k}=-8 \rightarrow 8,1=-35 \rightarrow 38$ \\
Measured Reflections & 19953 \\
Independent Reflections & 4324 \\
Observed Reflections $(\mathrm{I}>2 \sigma)$ & 3099 \\
Goodness-of-fit on $F^{2}$ & 1.003 \\
$R_{1}$ indice $(\mathrm{I}>2 \sigma)$ & 0.035 \\
$w R_{2}$ indice $(\mathrm{I}>2 \sigma)$ & 0.092 \\
\hline & \\
\hline
\end{tabular}
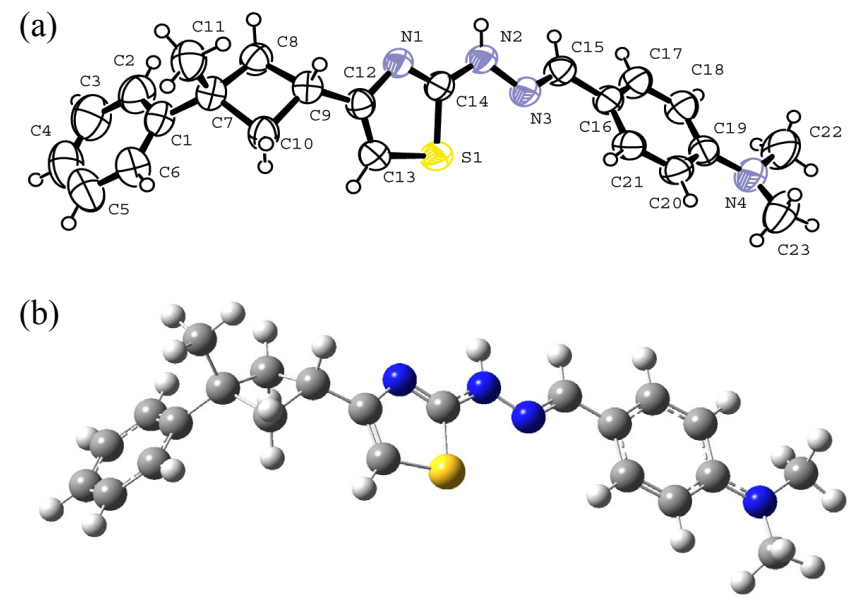

Figure 1. (a) ORTEP drawing of the basic crystallographic unit of the title compound (1), showing the atom-numbering scheme. Displacement ellipsoids are drawn at the $50 \%$ probability level and all $\mathrm{H}$ atoms are shown as small spheres of arbitrary radii. (b) Gaussian03View drawing of the title compound (1). 
$\AA$ ). The structure was solved by direct methods using SHELXS97 and refined by a full-matrix least-squares procedure using the program SHELXL-97. ${ }^{34}$ All non-hydrogen atoms were easily found from the difference Fourier map and refined anisotropically. All hydrogen atoms were included using a riding model and refined isotropically with $\mathrm{C}-\mathrm{H}=0.93-0.97 \AA$ and $\mathrm{N}-\mathrm{H}=0.86 \AA . \mathrm{U}_{\text {iso }}(\mathrm{H})=1.2 \mathrm{U}_{\text {eq }}(\mathrm{C}, \mathrm{N}), \mathrm{U}_{\text {iso }}(\mathrm{H})=1.5 \mathrm{U}_{\text {eq }}$ (for methyl group).

Theoretical methods. Theoretical calculations were carried out using semi-empirical AM1 and ab initio HF/6-31G(d, p) and density functional B3LYP/6-311G(d, p) and B3LYP/6-31G $(\mathrm{d}, \mathrm{p})$ quantum chemical methods. ${ }^{35-37}$ For modeling, the experimental data were supplemented by using semi-emprical and ab initio quantum chemical calculations. Molecular geometry is restricted and all the calculations are performed without specifying any symmetry for the title molecule by using Gaussian 03 Program package on a personal computer. ${ }^{38}$ In addition to these, vibrational frequencies for optimized molecular structures have been also calculated. No scale factor was used in the calculated frequencies. To identify low energy conformations, a selected degree of torsional freedom, $T(\mathrm{C} 8-\mathrm{C} 7-\mathrm{C} 1-\mathrm{C} 6)$, was varied from $-180^{\circ}$ to $+180^{\circ}$ in steps of $10^{\circ}$, and the molecular energy profile was obtained at the semi-empirical AM1 level.

\section{Result and Discussions}

Description of the crystal structure. The title compound contains thiazole, hydrazone, phenyl and cyclobutane moieties. Details of crystal parameters, data collection, structure solution and refinement are given in Table 1 and the crystal structure with the formula, $\mathrm{C}_{23} \mathrm{H}_{26} \mathrm{~N}_{4} \mathrm{~S}$, (I) shown in Figure 1. The central five-member thiazole ring is essentially planar, to within 0.0006 $\AA$. The dihedral angles between the phenyl ring $\mathrm{A}(\mathrm{C} 1$ through C6), cyclobutane ring $\mathrm{B}(\mathrm{C} 7$ through $\mathrm{C} 10)$, thiazole ring $\mathrm{C}(\mathrm{C} 12-$ C13-S1-C14-N1) and the other phenyl ring $\mathrm{D}(\mathrm{C} 16$ through $\mathrm{C} 21)$ are $38.69(6)^{\circ}(\mathrm{A} / \mathrm{B}), 49.30(7)^{\circ}(\mathrm{B} / \mathrm{C})$ and $41.49(5)^{\circ}(\mathrm{C} / \mathrm{D})$. Only some of bond distances in thiazole ring show partial double bond character so that C12-N1, S1-C13 and S1-C14 bond distances of 1.399(2), 1.724(2), 1.730(2) $\AA$ are showing the values of single bond character (see Table 2). The S-C bond distances are shorter than the accepted value for an $\mathrm{S}-\mathrm{C} \mathrm{sp}^{2}$ single bond with $1.76 \AA \AA^{39}$ It is worth noting that the $\mathrm{C} 14-\mathrm{N} 1$ bond distance value of 1.309(2) $\AA$ is falling in to the $\mathrm{C}=\mathrm{N}$ double bond distance region, and is shorter than the $\mathrm{C}=\mathrm{N}$ double bond distance found in related thiazole ring structure, ${ }^{40}$ in thiazole ring the $\mathrm{C} 12-\mathrm{C} 13$ bond distance of 1.344(2) $\AA$ is also showing the value of $\mathrm{C}=\mathrm{C}$ double bond character.

$\mathrm{C}$ and $\mathrm{D}$ rings are linked by the strictly planar $\mathrm{N} 2-\mathrm{N} 3=$ C15-C16 fragment and its torsion angle is $175.88(14)^{\circ}$. In hydrazone group, C15-N3 double bond distance of 1.262(2) $\AA$ is shorter than the $\mathrm{C}=\mathrm{N}$ bond distance found related hydrazone structures, i.e. 1.2810(19) $\AA^{41}$ and 1.272(2) $\AA^{42}$ The steric interaction between the substituent groups on the cyclobutane ring means that this ring derivates significantly from planarity. Literature values for the puckering of the cyclobutane ring are $29.03(13)^{\mathrm{o} 43}$ and $26.8(2)^{\mathrm{o}}$. $^{44}$ In this paper, the $\mathrm{C} 8 / \mathrm{C} 7 / \mathrm{C} 10$ plane forms a dihedral angle of $25.74(15)^{\circ}$ with the $\mathrm{C} 8 / \mathrm{C} 9 / \mathrm{C} 10$ plane.

The crystal structure does not exhibit intramolecular inter-
Table 2. Selected geometrical parameters of the title compound (1) with $\mathrm{X}$-ray structure, DFT and HF methods

\begin{tabular}{|c|c|c|c|c|}
\hline & Experimental & $\begin{array}{c}\text { B3LYP } \\
6-311 G \\
(d, p)\end{array}$ & $\begin{array}{c}\text { B3LYP } \\
6-31 G \\
(d, p)\end{array}$ & $\begin{array}{c}\mathrm{HF} \\
6-31 \mathrm{G} \\
(\mathrm{d}, \mathrm{p})\end{array}$ \\
\hline \multicolumn{5}{|l|}{ Bond lengths $(\AA)$} \\
\hline $\mathrm{S} 1-\mathrm{C} 13$ & $1.724(2)$ & 1.753 & 1.754 & 1.746 \\
\hline $\mathrm{S} 1-\mathrm{C} 14$ & $1.730(2)$ & 1.758 & 1.760 & 1.739 \\
\hline $\mathrm{N} 1-\mathrm{C} 12$ & $1.399(2)$ & 1.386 & 1.388 & 1.386 \\
\hline $\mathrm{N} 1-\mathrm{C} 14$ & $1.309(2)$ & 1.299 & 1.303 & 1.279 \\
\hline $\mathrm{N} 2-\mathrm{C} 14$ & $1.360(2)$ & 1.369 & 1.369 & 1.362 \\
\hline N2-N3 & $1.385(2)$ & 1.351 & 1.353 & 1.355 \\
\hline N3-C15 & $1.262(2)$ & 1.285 & 1.289 & 1.256 \\
\hline $\mathrm{N} 4-\mathrm{C} 19$ & $1.389(2)$ & 1.381 & 1.384 & 1.384 \\
\hline $\mathrm{N} 4-\mathrm{C} 22$ & $1.449(3)$ & 1.453 & 1.452 & 1.447 \\
\hline $\mathrm{N} 4-\mathrm{C} 23$ & $1.443(3)$ & 1.454 & 1.453 & 1.447 \\
\hline \multicolumn{5}{|l|}{ Bond angles $\left({ }^{\circ}\right)$} \\
\hline C12-N1-C14 & $109.22(12)$ & 110.67 & 110.33 & 110.70 \\
\hline N1-C14-N2 & $125.05(13)$ & 122.58 & 122.61 & 122.20 \\
\hline C14-N2-N3 & $114.28(12)$ & 121.30 & 121.13 & 119.58 \\
\hline $\mathrm{N} 2-\mathrm{N} 3-\mathrm{C} 15$ & $117.34(13)$ & 117.94 & 117.76 & 118.18 \\
\hline $\mathrm{N} 3-\mathrm{C} 15-\mathrm{C} 16$ & $121.83(14)$ & 122.96 & 122.73 & 122.77 \\
\hline C19-N4-C22 & $118.69(16)$ & 119.81 & 119.71 & 118.96 \\
\hline C19-N4-C23 & $118.79(16)$ & 119.97 & 119.85 & 119.09 \\
\hline \multicolumn{5}{|c|}{ Torsion angles $\left({ }^{\circ}\right)$} \\
\hline C9-C12-N1-C14 & $-179.34(13)$ & -179.81 & -179.85 & -179.70 \\
\hline $\mathrm{C} 12-\mathrm{N} 1-\mathrm{C} 14-\mathrm{N} 2$ & $178.54(13)$ & 179.78 & 179.80 & 178.01 \\
\hline N1-C14-N2-N3 & $167.36(14)$ & 179.89 & 180.00 & 170.00 \\
\hline C14-N2-N3-C15 & $169.83(14)$ & 179.62 & 179.55 & 170.95 \\
\hline $\mathrm{C} 18-\mathrm{C} 19-\mathrm{N} 4-\mathrm{C} 23$ & $164.70(19)$ & 171.93 & 172.37 & 166.97 \\
\hline $\mathrm{C} 20-\mathrm{C} 19-\mathrm{N} 4-\mathrm{C} 22$ & $-170.60(2)$ & -173.29 & -173.54 & -168.72 \\
\hline
\end{tabular}

Table 3. Hydrogen bond interaction of the title compound $(\mathbf{1})\left(\AA,{ }^{\circ}\right)$

\begin{tabular}{lcccc}
\hline Hydrogen bond $\left(\AA,{ }^{\circ}\right)$ & $\mathrm{D}-\mathrm{H}$ & $\mathrm{H} \cdots \mathrm{A}$ & $\mathrm{D} \cdots \mathrm{A}$ & $\mathrm{D}-\mathrm{H} \cdots \mathrm{A}$ \\
$\mathrm{N} 2-\mathrm{H} 2 \mathrm{~A} \cdots \mathrm{N} 1^{\mathrm{i}}$ & 0.86 & 2.29 & $3.037(2)$ & 145 \\
\hline
\end{tabular}

Symmetry code: (i): 1-x, 2-y, -z

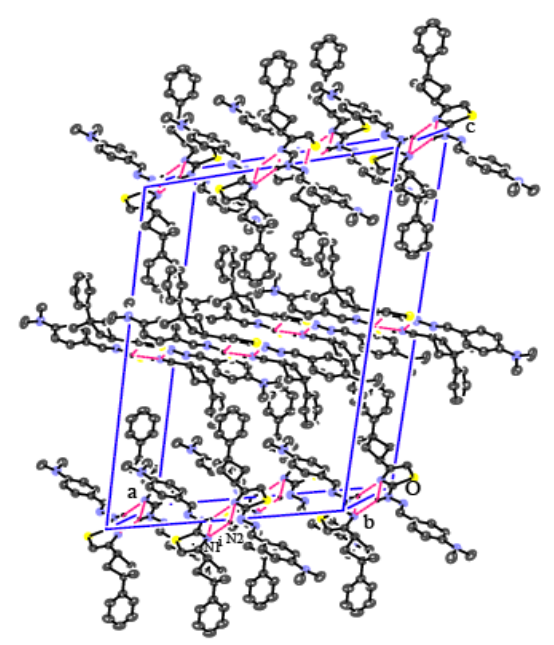

Figure 2. A partial packing diagram of the title compound (1). $\mathrm{N}-\mathrm{H} \cdots \mathrm{N}$ interaction has been shown as broken lines. Hydrogen atoms not involved in hydrogen bonding have been omitted [Symmetry code: (i): $1-\mathrm{x}, 2-\mathrm{y},-\mathrm{z}]$. 
action. There is, however, an intermolecular $\mathrm{N}-\mathrm{H} \cdots \mathrm{N}$ (head to head) hydrogen bonding, details of which are given in Table 3. In this hydrogen bonding, atom $\mathrm{N} 2$ of the molecule at $(\mathrm{x}, \mathrm{y}, \mathrm{z})$ acts as hydrogen-bond donor, via atom $\mathrm{H} 2 \mathrm{~A}$, to atom $\mathrm{N} 1$ of the molecule at (1-x, 2-y, -z), so generating by inversion a dimer, centered at $(1 / 2,1,0)$ and characterized by an $\mathrm{R}_{2}{ }^{2}(8)$ motif (see Figure 2). The $\mathrm{R}_{2}{ }^{2}(8)$ rings formed by hydrogen bonds are centered at $[\mathrm{n} / 2, \mathrm{~m} / 2, \mathrm{k}]$ and $[\mathrm{n} / 2, \mathrm{~m} / 2,1 / 2+\mathrm{k}](\mathrm{n}, \mathrm{m}$ and $\mathrm{k}$ are zero or integer). Beside of these dimers, the weak $\pi-\pi$ and $\pi \cdots$ ring interactions also stabilize to crystal packing.

Vibrational frequency. As mentioned in the Experimental section, the experimental FT-IR spectra was obtained in $\mathrm{KBr}$ discs using a Mattson 1000 FT-IR spectrometer, and shown in Figure 3. Vibrational frequencies calculated at B3LYP/6-311G $(d, p)$, B3LYP/6-31G(d, p) and HF/6-31G(d, p) levels. Some primary calculated harmonic frequencies are listed in Table 4 and compared with the experimental data. The descriptions concerning the assignment have also been indicated in the Table 4. Gauss-View Molecular Visualization program was used to assign the calculated harmonic frequencies. ${ }^{45}$ As seen from Table 4, the predicted IR spectra by using B3LYP/6-311G(d,

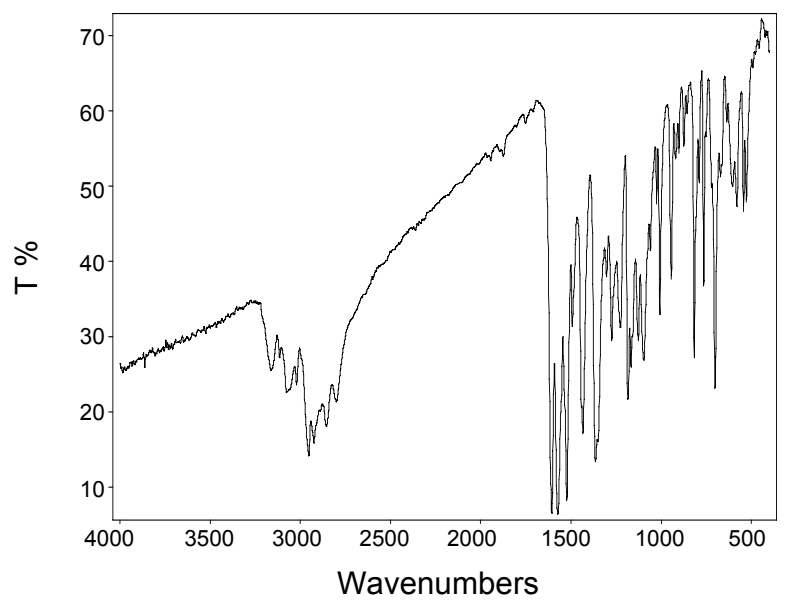

Figure 3. The experimental FT-IR spectrum of the title compound (1).

Table 4. Vibrational frequencies of the title compound (1) with X-ray structure, DFT and HF methods

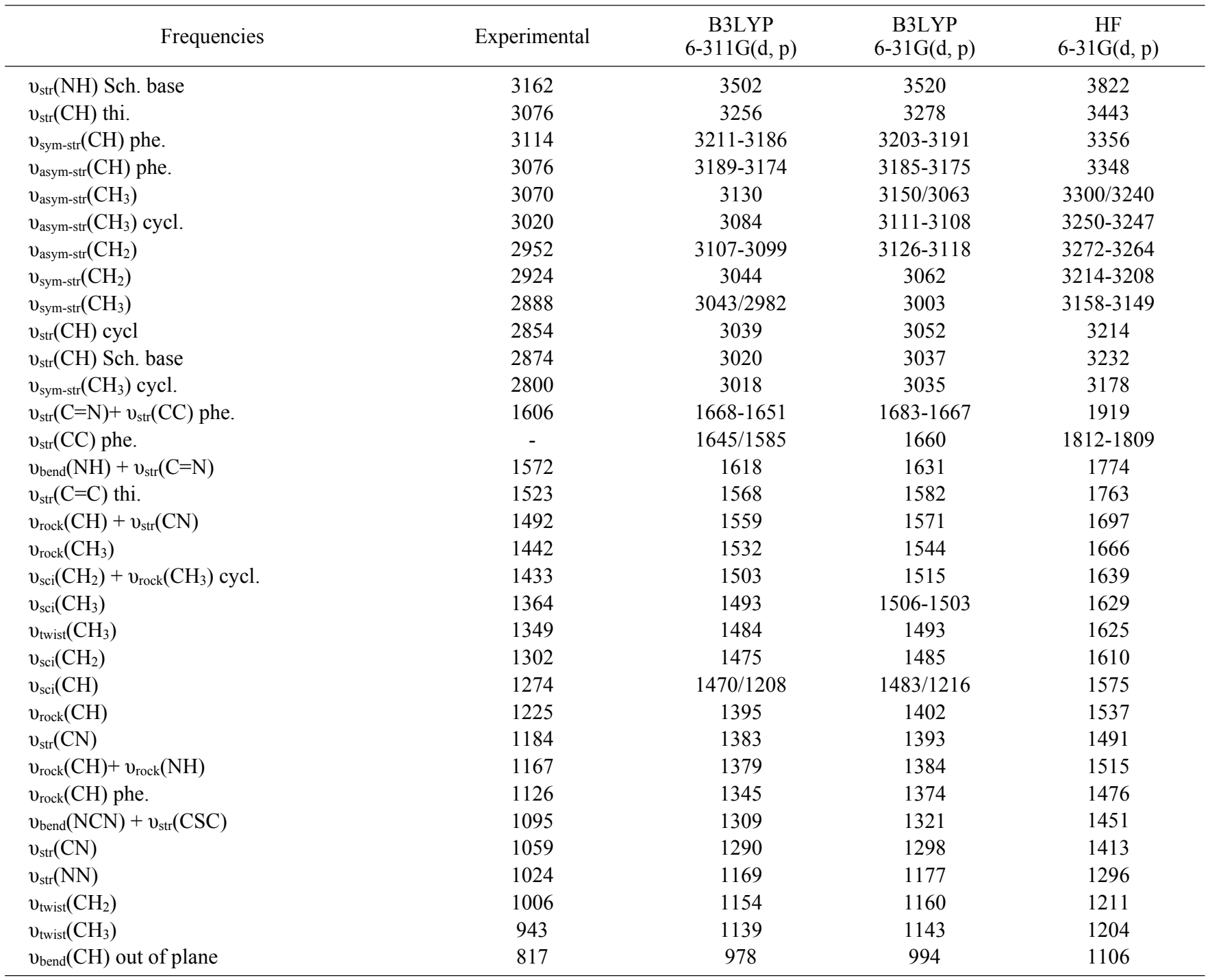

Sch. base: schiff base, thi: thiazole, phe: phenyl, cycl: cyclobutane, str: stretching, bend: bending, rock: rocking, twist: twisting, sci: scissorsing 
p) and B3LYP/6-31G(d,p) methods are consistent with those by HF/6-31G(d, p) method. It is well known that the calculated HF and DFT 'raw' or 'non-scale' harmonic frequencies could significantly overestimate experimental values due to lack of electron correlation, insufficient basis sets and anharmonicity. Much effort has been devoted to accurately reproducing experimental frequencies in theoretical calculations. The HartreeFock calculated results are usually more overestimated than the corresponding DFT ones. ${ }^{46}$ To compare these, we calculated the theoretical vibrational spectra of the title compound by using both HF/6-31G(d, p) and B3LYP/6-311G(d, p) with B3LYP/ $6-31 G(d, p)$ methods and compared with the experimental results.

The characteristic $v(\mathrm{CH})$ stretching vibrations of heteroaromatic structures are expected to appear in $3000-3100 \mathrm{~cm}^{-1}$ frequency ranges. ${ }^{47,48}$ In the present study, experimentally four $v$ (CH) stretching vibrations of the title compound (I) are observed at $3114,3076,2874$ and $2854 \mathrm{~cm}^{-1}$. The highest normal mode of vibration corresponds to the $v(\mathrm{CH})$ stretching in the thiazole ring, which is calculated at $3443 \mathrm{~cm}^{-1}$ for $\mathrm{HF} / 6-31 \mathrm{G}(\mathrm{d}, \mathrm{p}) \mathrm{me}-$ thod. On the other hand, the $\mathrm{CH}_{3}$ asymmetric and symmetric stretching frequencies are established at 3070, 3020, 2888 and $2800 \mathrm{~cm}^{-1}$ in infrared spectra. All this results are in good agreement with the literature values. ${ }^{47,49,50}$ As shown in Table 4, the experimentally determined vibrational bands of the compound were found to be significantly lower than calculated values; however, $v(\mathrm{NH})$ stretching vibration is observed at $3162 \mathrm{~cm}^{-1}$ and bending vibration is observed at $1572 \mathrm{~cm}^{-1}$ for experimental values. Due to $\mathrm{N}-\mathrm{H} \cdots \mathrm{N}$ intermolecular hydrogen bonding, it can be said that experimental $v(\mathrm{NH})$ bending vibration increases while $v(\mathrm{NH})$ stretching vibration decreases. ${ }^{51}$ Other essential characteristic vibrations of the title compound such as rocking, bending, scissorsing, out of plane bending, twisting are compared in Table 4. As a result, experimental frequency values are in good agreement with the calculated frequencies with HF and B3LYP methods.

Theoretical structures. Some selected geometric parameters experimentally obtained and theoretically calculated by HF/6$31 \mathrm{G}(\mathrm{d}, \mathrm{p})$, B3LYP/6-311G(d, p) and B3LYP/6-31G(d, p) methods are listed in Table 2. When the X-ray structure of the title compound is compared with B3LYP/6-311G(d,p) optimized counterpart (see Figure 4), conformational discrepancy is observed between its. The dihedral angles between A, B, C and D planes are calculated at $49.73^{\circ}(\mathrm{A} / \mathrm{B}), 47.55^{\circ}(\mathrm{B} / \mathrm{C})$ and $33.42^{\circ}$ $(\mathrm{C} / \mathrm{D})$ for $\mathrm{AM} 1$, at $36.79^{\circ}(\mathrm{A} / \mathrm{B}), 46.05^{\circ}(\mathrm{B} / \mathrm{C})$ and $0.93^{\circ}(\mathrm{C} / \mathrm{D})$ for $\mathrm{B} 3 \mathrm{LYP} / 6-311 \mathrm{G}(\mathrm{d}, \mathrm{p})$, at $28.36^{\circ}(\mathrm{A} / \mathrm{B}), 37.96^{\circ}(\mathrm{B} / \mathrm{C})$ and $38.17^{\circ}(\mathrm{C} / \mathrm{D})$ for B3LYP/6-31G(d, p) and at $36.18^{\circ}(\mathrm{A} / \mathrm{B}), 43.71^{\circ}$ $(\mathrm{B} / \mathrm{C})$ and $8.27^{\circ}(\mathrm{C} / \mathrm{D})$ for $36.79^{\circ}(\mathrm{A} / \mathrm{B}), 46.05^{\circ}(\mathrm{B} / \mathrm{C})$ and $0.93^{\circ}$ (C/D) for HF/6-31G(d, p).

For the optimized geometric parameters, various methods including HF method estimates some bond lengths well to some extent. $^{52-54}$ We noted that the experimental results belong to solid phase and theoretical calculations belong to gaseous phase. In the solid state, the existence of the crystal field along with the intermolecular interactions have connected the molecules together, which result in the differences of bond parameters between the calculated and experimental values. It is well known that DFT optimized bond lengths are usually longer and more

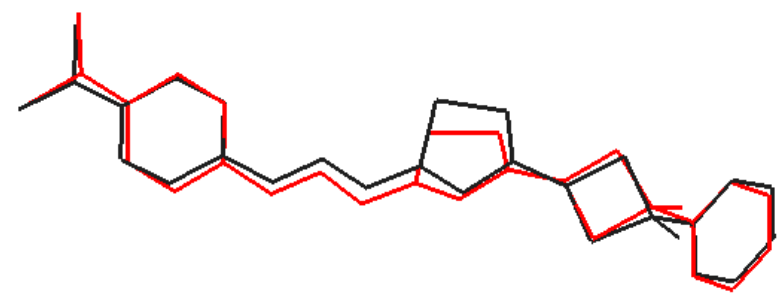

Figure 4. Atom-by-atom superimposition of the structures calculated (red)(B3LYP/6-311G(d,p)) over the X-ray structure (black) for the title compound. Hydrogen atoms have been omitted for clarity. The RMS overlay error of $0.601 \AA$ does not include hydrogen atoms.

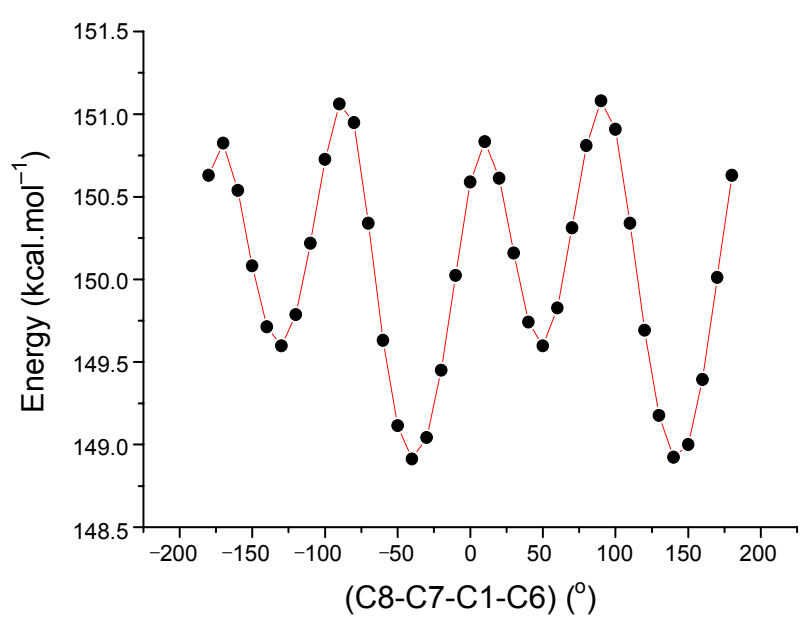

Figure 5. Molecular energy profile against the selected torsional degree T(C8-C7-C1-C6) of freedom for AM1 method.

accurate than HF, due to inclusion of electron correlation. However, according to our calculations, HF method correlates well for both bond length, bond angle and torsion angle compared with the other method (Table 2). The largest differences between experimental and calculated HF and B3LYP bond lengths are about $0.030 \AA$ and $0.034 \AA$, respectively. The bond angles provided by HF method is the closest to the experimental values (see Table 2). The largest difference is about $5.30^{\circ}$ in the case of HF method, while this difference is $7.02^{\circ}$ for B3LYP method. The same trend was also observed in torsion angles. The largest differences are $12.64^{\circ}$ and $2.64^{\circ}$ for B3LYP and HF methods, respectively. As a result, the optimized bond lengths, bond angles and torsion angles obtained by HF method show the best agreement with the experimental values.

Conformational analysis. In order to define the preferential position of the phenyl ring system with respect to the cyclobutane group, a preliminary search of low-energy structures was performed by using AM1 computation as a function of the selected torsion angle, $T(\mathrm{C} 8-\mathrm{C} 7-\mathrm{C} 1-\mathrm{C} 6)$. The respective value of the selected torsion angle is $151.74(15)^{\circ}$ in the X-ray structure, whereas the corresponding values in optimized geometries are $142.686^{\circ}$ for $\mathrm{AM} 1,143.251^{\circ}$ for $\mathrm{HF} / 6-31 \mathrm{G}(\mathrm{d}, \mathrm{p}), 142.169^{\circ}$ for B3LYP/6-31G(d, p) and 142.295 for B3LYP/6-311G(d, p). The molecular energy profile with respect to rotations about the selected torsion angle is presented in Figure 5. According to the results, the low-energy domains for $T(\mathrm{C} 8-\mathrm{C} 7-\mathrm{C} 1-\mathrm{C} 6)$ are 

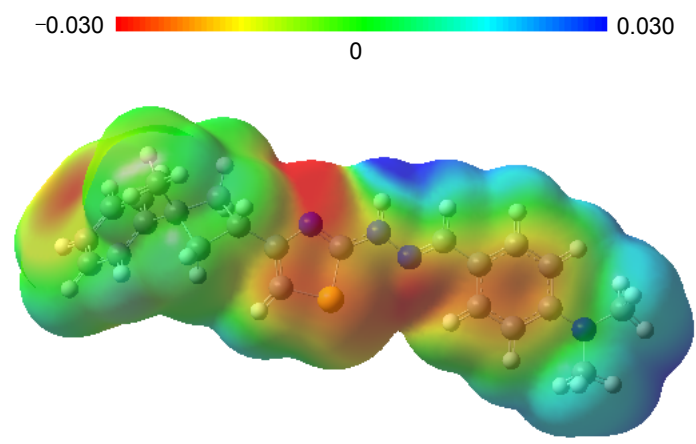

Figure 6. Molecular electrostatic potential map (in a.u.) of the title compound with the B3LYP/6-311G(d, p) method (with an isodensity value of 0.0004 a.u.).

located at -40 and $140^{\circ}$ with energies of 148.913 and 148.924 $\mathrm{kcal} \mathrm{mol}^{-1}$. As shown in Figure 5, the energy difference between the most favourable and most unfavourable conformers, which arises from the rotational potential barrier calculated with respect to the selected torsion angle, is calculated to be $1.920 \mathrm{kcal}$ $\mathrm{mol}^{-1}$.

The molecular energy can be divided into bonded and nonbonded contributions. The bonded energy is considered to be independent of torsional angle changes and therefore vanished when relative conformer energies are calculated. The non-bonded energy is further separated into torsional steric and electrostatic terms. ${ }^{55}$ Since the title compound contains no intramolecular hydrogen bond, it can be deduced from the computational results that the most stable conformer of the title compound is principally determined by the non-bonded torsional energy term affected by packing of the molecules.

Molecular electrostatic potential. The molecular electrostatic potential (MEP) is related to the electronic density and is a very useful descriptor for determining sites for electrophilic attack and nucleophilic reactions as well as hydrogen-bonding interactions. ${ }^{56-58}$ To predict reactive sites for electrophilic and nucleophilic attack for the title molecule, MEP was calculated at the B3LYP/6-311G(d, p) optimized geometry. The negative (red) regions of MEP were related to electrophilic reactivity and the positive (blue) regions to nucleophilic reactivity shown in Figure 6. As can be seen from the figure, there is possible site on the title compound for electrophilic attack. The negative region is localized on the unprotonated nitrogen atom of the thiazole ring, N1, with a maximum value of -0.030 a.u. However, maximum positive region is localized on atom $\mathrm{N} 2$ probably due to the hydrogen, with a maximum value of 0.030 a.u. These results provide information concerning the region where the compound can interact intermolecularly and bond metallically. Therefore, Figure 6 confirms the existence of an intermolecular $\mathrm{N}-\mathrm{H} \cdots \mathrm{N}$ interaction between the protonated and unprotonated $\mathrm{N}$ atoms of the thiazole ring and hydrazone group.

Frontier molecular orbital analysis. The calculations indicate that the compound has 104 occupied molecular orbitals (MOs). The highest occupied molecular orbital (HOMO) energies, the lowest unoccupied molecular orbital (LUMO) energies, the energy gap for mentioned molecule in above have calculated and given in Table 5. The frontier molecular orbitals play an im-
Table 5. Molecular energy profile against the selected torsional degree T(C8-C7-C1-C6) of freedom for AM1 method

\begin{tabular}{|c|c|c|c|}
\hline Energies & $\begin{array}{c}\text { B3LYP/6-311 } \\
\text { G(d,p) }\end{array}$ & $\begin{array}{c}\text { B3LYP/6-31 } \\
\text { G(d,p) }\end{array}$ & $\begin{array}{c}\mathrm{HF} / 6-31 \\
\mathrm{G}(\mathrm{d}, \mathrm{p})\end{array}$ \\
\hline Homo (a.u.) & -0.182 & -0.174 & -0.263 \\
\hline Lumo (a.u.) & -0.044 & -0.035 & 0.107 \\
\hline$\Delta$ (a. u.) $(\mathrm{eV})$ & $0.138(3.765)$ & $0.139(3.783)$ & $0.370(10.070)$ \\
\hline Total Energies (a.u.) & -1509.540 & -1509.281 & 1501.384 \\
\hline Dipole moment (Debye) & 5.0765 & 4.8880 & 4.5051 \\
\hline Homo-1 (a.u.) & -0.214 & -0.206 & -0.299 \\
\hline Homo-2 (a.u.) & -0.239 & -0.230 & -0.314 \\
\hline Lumo+1 (a.u.) & -0.009 & 0.003 & 0.144 \\
\hline Lumo+2 (a.u.) & -0.004 & 0.007 & 0.152 \\
\hline
\end{tabular}

1 a.u. $=27.2116 \mathrm{eV}$

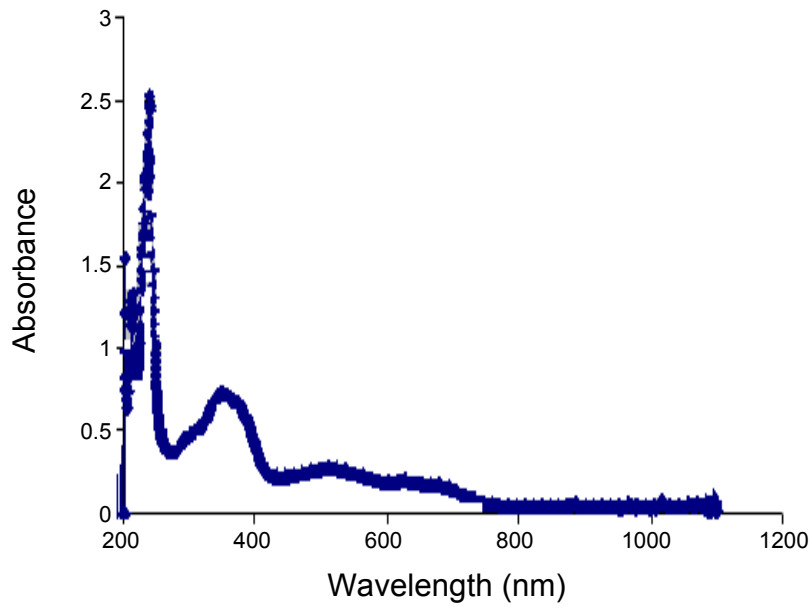

Figure 7. The experimental UV-vis absorption spectra of the title compound (1).

portant role in the electric and optical properties, as well as in UV-vis spectra and chemical reactions. ${ }^{59}$ Based on B3LYP/6311G(d, p), B3LYP/6-31G(d, p) and HF/6-31G(d, p) optimized geometry, the total energy of the title compound has been calculated by this three methods, which are $-1509.540,-1509.281$ and -1501.384 a.u., respectively. An electronic system with a larger HOMO-LUMO gap should be less reactive than one having a smaller gap. ${ }^{60}$ In the present study, the HOMO-LUMO gap values of the molecule are at 3.765, 3.783 and $10.070 \mathrm{eV}$ for B3LYP/6-311G(d, p), B3LYP/6-31G(d, p) and for HF/6$31 \mathrm{G}(\mathrm{d}, \mathrm{p})$ methods, respectively, as seen in Table 5 .

The UV-vis absorption spectra of the title compound were recorded in the $\mathrm{CHCl}_{3}$ solutions. The compound exhibits absorption peaks in the UV-visible region. The UV-vis absorption spectra of the title compound is shown in Figure 7. The experimentally absorption peaks are observed at 349, $239 \mathrm{~nm}$ for the title compound. It can be seem that these peaks equal to $\mathrm{n} \rightarrow \pi^{*}$ and $\pi \rightarrow \pi^{*}$ transitions. 3D plots of the HOMO-2, HOMO-1, $\mathrm{HOMO}, \mathrm{LUMO}, \mathrm{LUMO}+1, \mathrm{LUMO}+2$ and the corresponding energy levels for the title compound are shown in Figure 8. The theoretically electronic transfers (ET) for the compound B3LYP/6-311G(d, p) and B3LYP/6-31G(d, p) basis sets are at 330, 243 and 329, $234 \mathrm{~nm}$ to correspond to the UV-vis spectral 

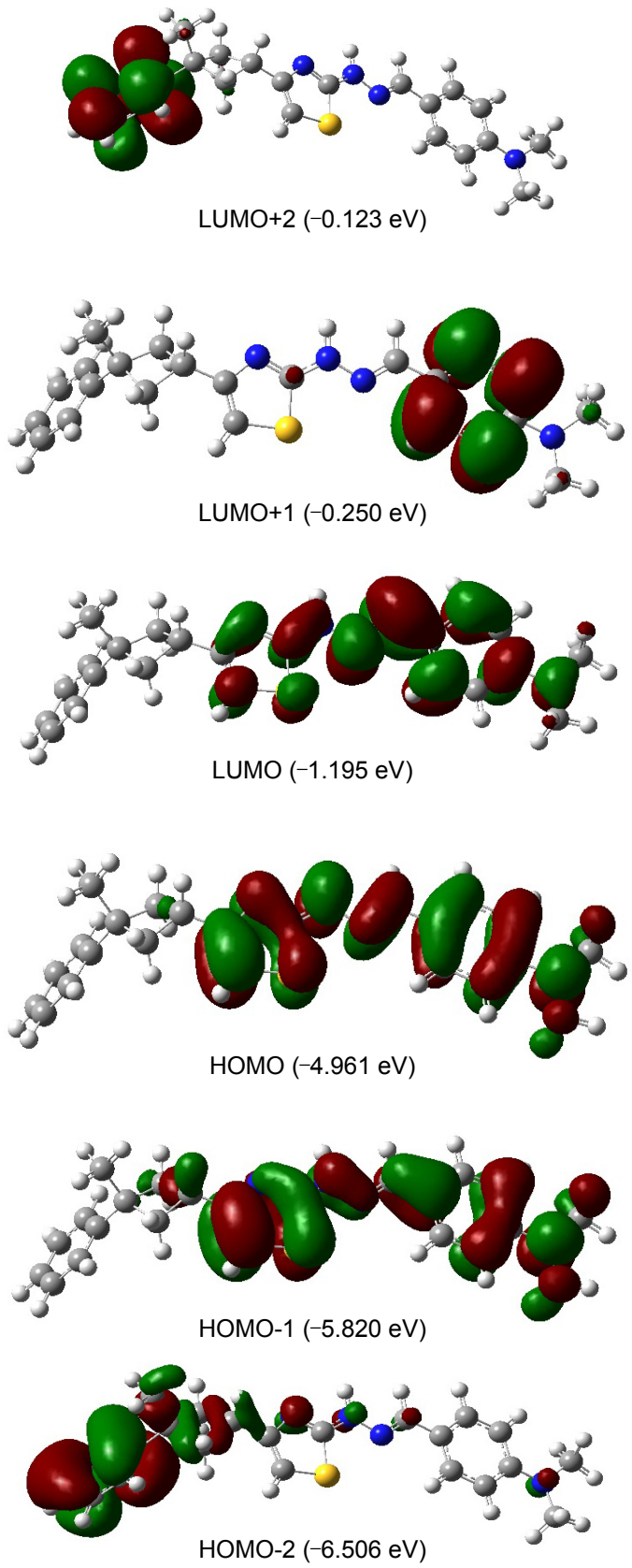

Figure 8. Molecular orbital surfaces and energy levels given in parentheses for the HOMO-2, HOMO-1, HOMO, LUMO, LUMO+1 and $\mathrm{LUMO}+2$ of the title compound have been computed with the B3LYP/ $6-311 \mathrm{G}(\mathrm{d}, \mathrm{p})$ method. The positive phase is red, and the negative phase is green.

absorption peaks, and the corresponding electronic transfers happened between HOMO and LUMO, HOMO and LUMO+1, respectively. The bigger theoretical absorption wavelengths of the compound have slight blue-shifts comparing with the corresponding experimental ones.

Natural population analysis indicates that the electronic transitions are mainly derived from the contributions of bands $\pi \rightarrow$ $\pi^{*}$ as reported literature. ${ }^{61}$ As shown from Figure 7, the electron clouds of the HOMO and HOMO- 1 are delocalized on the thiazole, hydrazone bridge and phenyl ring but HOMO-2 is delocalized on the other phenyl ring. These orbitals are seem to be $\pi$-bonding type orbital. LUMO is found mainly delocalized on thiazole, hydrazone bridge and phenyl ring, but LUMO+1 and $\mathrm{LUMO}+2$ are found mainly delocalized on different parts of the title molecule. In all cases, LUMOs are $\pi^{*}$-anti-bonding orbitals.

\section{Conclusions}

In this study, we have synthesized a novel hydrazone compound, $\mathrm{C}_{23} \mathrm{H}_{26} \mathrm{~N}_{4} \mathrm{~S}$, and characterized by using spectroscopic (IR, ${ }^{1} \mathrm{H}-\mathrm{NMR},{ }^{13} \mathrm{C}-\mathrm{NMR}, \mathrm{UV}$-vis) and structural (XRD) techniques. The X-ray structure is found to be very slightly different from its optimized counterparts, and the crystal structure is stabilized by $\mathrm{N}-\mathrm{H} \cdots \mathrm{N}$-type hydrogen bond between the protonated $\mathrm{N}$ atom of hydrazone group and unprotonated $\mathrm{N}$ atom of adjacent thiazole ring as well as by van der Waals forces. The results of the HF method show a better fit to experimental values than B3LYP in evaluating geometrical parameters. It is noted here that the experimental results are for the solid phase and the theoretical calculations are for the gaseous phase. In the solid state, the existence of the crystal field together with the intermolecular interactions holds the molecules together, which results in differences between the calculated and experimental values for the bond parameters. Despite the differences observed in the geometric parameters, the general agreement is good and the theoretical calculations support the solid-state structures. However, it can be seen from the theoretical results that the B3LYP method is more appropriate than the HF method for the calculation of vibrational frequencies. The calculated MEP map agrees well with the solid-state interactions. As mentioned in the introduction, this compound has been synthesized as a part of our ongoing research program. According to the observed results, there is a good relationship between the results of the present study and expected functionalities from the structure of the molecule.

Supplementary Data. Crystallographic data for the structural analysis have been deposited with the Cambridge Crystallographic Data Centre, CCDC No 748348 Copies of this information may be obtained free of charge from the Director, CCDC, 12 Union Road, Cambridge CB2 1EZ, UK (fax: +44-1223336033; e-mail: deposit@ccdc.cam.ac.uk or www: http://www. ccdc.cam.ac.uk).

Acknowledgments. The authors wish to acknowledge the Faculty of Arts and Sciences, Ondokuz Mayis University, Turkey, for the use of the STOE IPDS-II diffractometer (purchased under grant F.279 of the University Research Fund).

\section{References}

1. Zollinger, H. Colour Chemistry Syntheses Properties and Applications of Organic Dyes and Pigments, 2nd ed.; Weinheim: VCH, 1991.

2. Koparır, M.; Cansız, A.; Ahmedzade, M.; Çetin, A. Heteroat. Chem. 2004, 15, 26.

3. Ahmedzade, M.; Çukurovali, A.; Koparır, M. J. Chem. Soc. Pak. 
2003, 25, 51

4. Coghi, L.; Lanfredi, A. M. M.; Tripicchio, A. J. Chem. Soc. Perkin. Trans. 1976, 2, 1808.

5. Saprykina,V. A.; Vinogradova, V. I.; Ambartsumova, R. F.; Ibragimov, T. F.; Shakhidoyatov, Kh. M. Chem. Nat. Compd. 2006, 42, 4470.

6. Hadjipavlou-Litina, J. D.; Geronikaki, A. Arzneim Forsch/Drug. Res. 1996, 46, 805.

7. Holla, B. S.; Malini, K. V.; Rao, B. S.; Sarojini, B. K.; Kunari, N. S. Eur. J. Med. Chem. 2003, 38, 313.

8. Tarafder, M. T. H.; Jin, K. T.; Crouse, K. A.; Ali, A. M.; Yamin, B. M.; Fun, H.-K. Polyhedron 2002, 21, 2547.

9. Guerriero, P.; Tamburini, S.; Vigato, P. A. Coord. Chem. Rev. 1995, 139, 17.

10. Sreekala, R.; Yusuff, K. K. M. React. Kinet. Catal. Lett. 1992, 48, 575.

11. Das, N. N.; Dash, A. C. Polyhedron 1995, 14, 1221.

12. Williams, D. R. Chem. Rev. 1972, 72, 203.

13. Tsapkov, V. I. Russ. J. Gen. Chem. 2002, 72, 276.

14. Ghosh, S.; Bandyopadhyay, T. K. Trans. Met. Chem. 1985, 10, 57.

15. Shan, S.; Xu, D.-J.; Wu, J.-Y.; Chiang, M. Y. Acta Crystallogr. 2002, E58, o1444.

16. Bosan, W. S.; Shank, R. C.; MacEwen, J. D.; Gaworski, C. L.; Newberne, P. M. Carcinogenesis 1987, 8, 439.

17. Roberge, A.; Gosslin, C.; Charbonneau, R. Biochem. Pharmacol. 1971, 20, 2231.

18. Waterfield, C. J.; Asker, D. S.; Timbrell, J. A. Chem. Biol. Int. $1997,107,157$.

19. Rothgery, E. F. Kirk-Othmer Encyclopedia of Chemical Technology, 5th ed.; Wiley: Hoboken, N. J. 2005; 27, pp 22957.

20. Schmidt, E.W. Hydrazine and its Derivatives: Preparation, Properties, Applications, 2nd ed.; Wiley: Hoboken, N. J. 2001.

21. Tezcan, H.; Tunç, T.; Şahin, E.; Yagbasan, R. Analy. Sci. 2004, 20, $\mathrm{x} 137$.

22. Townshend, A.; Wheatly, R. A. Analy. 1998, 123, 1041.

23. Cukurovali, A.; Yilmaz, I.; Gur, S.; Kazaz, C. Eur. J. Med. Chem. 2006, 41, 201.

24. Dinçer, M.; Avcı, D.; Şekerci, M.; Atalay, Y. J. Mol. Model. 2008, 14,823 .

25. Özdemir, N.; Dinçer, M.; Çukurovalı, A.; Büyükgüngör, O. J. Mol. Model. 2009, 15, 1435.

26. Misra, N.; Prasad, O.; Sinha, L.; Pandey, A. J. Mol. Struct. (Theochem.) 2007, 822, 45.

27. Jian, F.; Zhao, P.; Guo, H.; Li, Y. Spectrochim. Acta 2008, A69, 647.

28. Choo, J.; Yoo, S.; Moon, S.; Kwon, Y.; Chung, H. Vibr. Spectrosc. 1998, 17, 173

29. Forsyth, D. A.; Sebag, A. B. J. Am. Chem. Soc. 1997, 119, 9483.

30. Cimino, P.; Gomez-Paloma, L.; Duca, D.; Riccio, R.; Bifulco, G. Magn. Reson. Chem. 2004, 42, 26.

31. Friesner, R. A.; Murphy, R. B.; Beachy, M. D.; Ringnalda, M. N.; Pollard, W. T.; Dunietz, B. D.; Cao, Y. J. Phys. Chem. 1999, A103 (13), 1913.

32. Rulìsek, L.; Havlas, Z. Int. J. Quantum Chem. 2003, 91, 504.

33. Ziegler, T. Chem. Mater. Sci. 1997, 69.

34. Sheldrick, G. M. SHELXS-97 and SHELXL-97, Univ. Gottingen, Germany, 1997.

35. Lee, C.; Yang, W.; Parr, R. G. Phys. Rev. 1988, B37, 785.

36. Becke, A. D. J. Chem. Phys. 1993, $98,5648$.

37. Ditchfield, R.; Hehre, W. J.; Pople, J. A. J. Chem. Phys. 1971, 54,
724

38. Frisch, M. J.; Trucks, G. W.; Schlegel, H. B.; Scuseria, G. E.; Robb, M. A.; Cheeseman, J. R.; Montgomery J. A.; Jr., Vreven, T.; Kudin, K. N.; Burant, J. C.; Millam, J. M.; Iyengar, S. S.; Tomasi, J.; Barone, V.; Mennucci, B.; Cossi, M.; Scalmani, G.; Rega, N.; Petersson, G. A.; Nakatsuji, H.; Hada, M.; Ehara, M.; Toyota, K.; Fukuda, R.; Hasegawa, J.; Ishida, M.; Nakajima, T.; Honda, Y.; Kitao, O.; Nakai, H.; Klene, M.; Li, X.; Knox, J. E.; Hratchian, H. P.; Cross, J. B.; Bakken, V.; Adamo, C.; Jaramillo, J.; Gomperts, R.; Stratmann, R. E.; Yazyev, O.; Austin, A. J.; Cammi, R.; Pomelli, C.; Ochterski, J. W.; Ayala, P. Y.; Morokuma, K.; Voth, G. A.; Salvador, P.; Dannenberg, J. J.; Zakrzewski, V. G.; Dapprich, S.; Daniels, A. D.; Strain, M. C.; Farkas, O.; Malick, D. K.; Rabuck, A. D.; Raghavachari, K.; Foresman, J. B.; Ortiz, J. V.; Cui, Q.; Baboul, A. G.; Clifford, S.; Cioslowski, J.; Stefanov, B. B.; Liu, G.; Liashenko, A.; Piskorz, P.; Komaromi, I.; Martin, R. L.; Fox, D. J.; Keith, T.; AlLaham, M. A.; Peng, C. Y.; Nanayakkara, A.; Challacombe, M.; Gill, P. M. W.; Johnson, B.; Chen, W.; Wong, M. W.; Gonzalez, C.; Pople, J. A. Gaussian 03. Revision E.01. Gaussian Inc., Wallingford, CT, 2004.

39. Allen, F. H. Acta Crystallogr. 1984, B40, 64.

40. Yüksektepe, Ç.; Çalışkan, N.; Yılmaz, I.; Çukurovali, A. Acta Crystallogr. 2006, E62, o2762.

41. Liu, G.; Liu, L.; Jia, D.; Yu, K. J. Chem. Crystallogr. 2005, 35, 497. 42. Ma, Q.; Lu, L.-P.; Zhu, M.-L. Acta Crystallogr. 2008, E64, o2026.

43. Yüksektepe, Ç.; Saraçoğlu, H.; Koca, M.; Çukurovali, A.; Çalışkan, N. Acta Crystallogr. 2004, C60, o509.

44. Yüksektepe, Ç.; Soylu, M. S.; Saraçoğlu, H.; Yılmaz, I.; Çukurovali, A.; Çalışkan, N.; Acta Crystallogr. 2005, E61, o1158.

45. Dennington, R. I. I.; Keith, T.; Millam, J. Gauss View, Version 4.1.2. Semichem Inc, Shawnee Mission, KS, 2007.

46. Zhou, W.; Lu, J.; Zhang, Z.; Zhang, Y.; Cao, Y.; Lu, L.; Yang, X. Vibr. Spectrosc. 2004, 34, 199.

47. Arslan, H.; Algül, O. Int. J. Mol. Sci. 2007, 8, 760.

48. Siddiqui, S. A.; Dwivedi, A.; Singh, P. K.; Hasan, T.; Jain, S.; Prasad, O.; Misra, N. J. Struc. Chem. 2009, 50, 411.

49. Sundaraganesan, N.; Kumar, K. S.; Meganathan, C.; Joshua, B. D. Spectrochim. Acta 2006, A65, 1186.

50. Krishnakumar, V.; Ramasamy, R. Spectrochim. Acta 2005, A62, 570.

51. Silverstein, R. M.; Bassler, G. C.; Morrill, T. C. Spectrometric Identification of Organic Compounds; John Wiley \& Sons: New York, 1963.

52. Wheeless, C. J. M.; Zou, X.; Liu, R. J. Phys. Chem. 1995, 99(33), 12488.

53. Lee, S. Y.; Boo, B. H. J. Phys. Chem. 1996, 100, 15073.

54. Atalay, Y.; Avc1, D.; Başoğlu, A.; Okur, I. J. Mol. Struct. (Theochem.) 2005, 713, 21 .

55. Weiqun, Z.; Baolong, L.; Yang, C.; Yong, Z.; Xujie, L.L.Y.J. Mol. Struct. (Theochem.) 2005, 715, 117.

56. Scrocco, E.; Tomasi, J. Adv. Quant. Chem. 1979, 11, 115.

57. Luque, F. J.; Lopez, J. M.; Orozco, M. Theor. Chem. Acc. 2000, $103,343$.

58. Okulik, N.; Jubert, A. H. Internet Electron. J. Mol. Des. 2005, 4, 17.

59. Fleming, I. Frontier Orbitals and Organic Chemical Reactions; Wiley: London, 1976.

60. Kurtaran, R.; Odabaşoğlu, S.; Azizoğlu, A.; Kara, H.; Atakol, O. Polyhedron 2007, 26, 5069.

61. Sun, Y.-X.; Wei, W.-X.; Hao, Q.-L.; Lu, L.-D.; Wang, X. Spectrochim. Acta 2009, A73, 772 . 